\title{
A INFLUÊNCIA DO NÍVEL DE TRANSPARÊNCIA DA GESTÃO PÚBLICA NA QUANTIDADE DE DISCLOSURE INFORMACIONAL DOS MUNICÍPIOS CAPIXABAS
}

\section{THE INFLUENCE OF THE TRANSPARENCY LEVEL OF THE PUBLIC MANAGEMENT IN THE QUANTITY OF INFORMATION DISCLOSURE OF THE CAPIXABAS MUNICIPALITIES}

"0 artigo foi aprovado e apresentado no XI Congresso da Associação Nacional de Programas de Pós-graduação em Ciências Contábeis - ANPCONT, realizado de 3 a 6 de junho de 2017, em Belo Horizonte (MG)"

\section{RESUMO}

Apesar de a literatura ressaltar a relevância do disclosure como instrumento de prestação de contas das empresas, e do governo aos seus stakeholders e à sociedade, não necessariamente a maior quantidade dessas informações geram um maior nível de accountability. Isso porque o nível do disclosure pode ser influenciado por características como relevância, tempestividade e compreensibilidade. Este estudo objetiva verificar o efeito do nível de transparência da gestão pública sobre a quantidade de disclosure entregue pelos gestores municipais. Para tanto, foram coletadas informações nos sites dos portais de transparência dos 78 municípios do Estado do Espírito Santo no período de 2013 a 2016. Os resultados sugerem uma relação inversa entre o nível de transparência com foco em boas prática e interatividade com quantidade de disclosure compulsório e voluntário, o que pode indicar um trade-off entre essas características do disclosure informacional, e também a preferência do gestor por cumprir a lei em detrimento de gerar maior quantidade de informações.

Palavras-chave: Disclosure, Transparência da Gestão Pública, Informação Compulsória e Voluntária.

\begin{abstract}
Although the literature highlights the relevance of disclosure as an instrument of accountability of companies and government to their shareholders and society, the greater value of this information generated at a higher level of responsibility is not allowed. This is because the level of disclosure can be influenced by features such as relevance, timeliness, and comprehensibility. This objective study aims to verify the effect of the level of transparency of public management on the amount of disclosure provided by municipal managers. To this end, information was collected from the websites of the transparency portals of the 78 municipalities of Espirito Santo from 2013 to 2016. The results suggests an inverse relationship between the level of transparency focused on good practices and interactivity with the amount of mandatory and voluntary disclosure, or that may indicate a trade-off between these information disclosure characteristics and also a manager's preference for enforcing the law rather than generating more information.
\end{abstract}

Keywords: Disclosure, Transparency of Public Management, Compulsory and Voluntary Information.
Paulo Sergio Torres da Silva Mestre em Ciências Contábeis pela Fucape Business School. Especialista em Contabilidade Gerencial pela UFES Graduado em Ciências Contábeis pela UFES. Docente do curso de Ciências Contábeis no Centro Universitário FAESA. Contato: Rua João Baptista Parra, 600, Enseada do Suá, Vitória, ES CEP: 29.050-375

E-mail: psilva@sefaz.es.gov.br

Danilo Soares Monte-mor Doutor em Administração e Ciências Contábeis pela Fucape Business School. Especialista em Métodos Quantitativos, Métodos de Otimização, Contabilidade e Economia, com ênfase em Finanças e Accounting Based Valuation Models. Graduado em Matemática pela Universidade Federal de Viçosa (UFV). Docente dos cursos de Mestrado e Graduação na Fucape Business School. Contato: Av. Fernando Ferrari, 1358, Boa Vista, Vitória, ES, CEP: 29.075-505 E-mail: danilo@fucape.br

Victor Rangel dos Santos Rodrigues

Graduando em Economia pela Fucape Business School. Contato: Av. Fernando Ferrari, 1358, Boa Vista, Vitória, ES, CEP: 29.075-505. E-mail: victorrangelrodrigues@gmail.com 


\section{INTRODUÇÃO}

Desde os trabalhos seminais de Akerlof (1970) e Spence (1973), a assimetria informacional é um assunto amplamente estudado na literatura econômica. Uma de suas aplicações, a qual este trabalho se debruça, é sobre o estudo da assimetria informacional entre a sociedade e seus governantes.

Apesar de a publicidade estar consagrada como princípio constitucional, dada a importância do gestor em fornecer informações e prestar contas ao cidadão (SUNDFELD, 1995), ela não é o suficiente pois, ainda que a informação seja pública, poderá não ser necessariamente relevante, tempestiva e compreensível ao cidadão (AVELINO et al., 2014). Nesse sentido, a transparência, que tem uma abrangência maior do que a publicidade, visa não somente cumprir as determinações legais, mas garantir políticas de gestão responsável que permitam à população exercer a cidadania (PLATT NETO et al., 2005).

Ao relacionar transparência da gestão pública com a quantidade de informações sobre atos e resultados das organizações, ou disclosure (ARAÚJO, 2013), disponibilizadas à sociedade, verifica-se formas de influência do gestor que afetam a estrutura do setor responsável pela contabilidade, influenciando, assim, na escolha contábil. São elas: Fonte de informação; Data do reconhecimento; na determinação do momento do registro contábil; Estimativa de valores; Escolha de como avaliar, na escolha dos métodos que serão adotados; Escolha do que divulgar; sua posição hierárquica dentro da entidade (SILVA, NIYAMA, 2012). Apesar de existirem considerações éticas que exercem ampla influência nas escolhas contábeis (HENDRIKSEN, BREDA, 1999), a literatura mapeia outras características dos gestores que não são fatores éticos e que possuem influência nessas escolhas, como formação e experiências anteriores, habilidade do gestor, capacidade do gestor de gerar confiança de empregados, entre outras características pessoais. (BAMBER, JIANG, WANG, 2010; GE, MATSUMOTO, ZHANG, 2011; LEWIS et al., 2013, DEMERJIAN et al., 2013; GARRET, HOITASH, PRAWITT, 2014; KOESTER, SHEVLIN, WANGERIN, 2016)

Na esfera pública, o nível de transparência das informações sobre a gestão das contas públicas tem por base a Lei Complementar $n^{\circ}$ 131/2009 e a Lei $n^{\circ}$ 12.527/2011, denominadas Lei de Acesso à Informação (LAI), as quais exigem que as informações sejam dispostas em tempo real contendo todas as especificações de forma detalhada sobre a execução orçamentária e financeira.

Mesmo com a obrigatoriedade legal, as informações são evidenciadas conforme práticas e interesses do gestor público, não garantem informatividade e transparência, podendo limitar, ou não, a compreensão dos usuários, fato que não confere accountability governamental (SLOMSKI, 2000; NAKAGAWA, 2007). O disclosure, por ser uma das principais formas de comunicação entre o gestor público e os usuários das informações, é um grande desafio para o setor público, pois a prestação de contas é um dever, às vezes empírico (tipicamente legal), às vezes moral, e surgem da responsabilidade que os indivíduos e as organizações têm para oferecer “contas” das atividades (GRAY, 2000).

Tendo como objetivo verificar se a transparência da gestão pública influencia na quantidade de disclosure dos relatórios informacionais dos municípios capixabas, o presente estudo baseia-se na análise das informações voluntárias e compulsórias distribuídas nos âmbitos das informações: Gerais; Adicionais; do Layout dos Relatórios; dos Relatórios Adicionais; da Situação Fiscal e Financeira; Ambientais e Legais dos municípios capixabas em relação à transparência. O estudo propõe a seguinte hipótese: Há uma associação negativa entre o nível de transparência da gestão pública e quantidade de disclosure para os municípios capixabas.

Para tanto, foi construído um classificador de disclosure a partir dos modelos estruturados por Lima (2009) e Avelino (2011) correlacionando-o ao nível de transparência baseado nos dados do Ministério Público do Estado do Espírito Santo.

A metodologia utilizada nesta pesquisa consistiu modelo econométrico de regressão em painel com efeito fixo para a análise da influência do nível de transparência da gestão pública na quantidade de disclosure compulsório e voluntário dos municípios no período de 2013 a 2016.

Apesar da literatura brasileira sobre disclosure ser ampla, a maioria das pesquisas concentram-se no setor privado (NIYAMA; DANTAS; ZENDERSKY, 2005; LANZANA, 2004; LIMA, 2009; ROVER, 2012; LO; RAMOS; ROGO, 2017), porém, são observados alguns estudos na área pública (AVELINO, 2011; BEUREN; SANTOS, 2013; CRUZ et al., 2012). Assim, este estudo visa contribuir no preenchimento de uma lacuna existente quanto à discussão acadêmica e conceitual do tema relacionado à contabilidade pública. A pesquisa também avança na modificação do modelo de disclosure de Avelino et al. (2011) com a inclusão dos quesitos legais (informações legais - voluntárias) trazendo para a teoria a análise da relação entre nível de transparência da gestão pública com a quantidade do disclosure, tanto para as informações compulsórias quanto para as voluntárias.

Os resultados alcançados demonstraram uma associação negativa entre o nível de transparência (baseado na lei de acesso à informação - LAI, com foco em boas práticas e interatividade) e quantidade de disclosure, tanto para as informações compulsórias quanto para as voluntárias. Há indicativos de um possível trade-off entre quantidade e qualidade, e também da preferência dos gestores municipais em valorizar a obrigatoriedade legal, no cumprimento da LAI (Lei de Acesso à Informação) em detrimento de produzir maior quantidade de informação, ou seja, o gestor preocupa-se em cumprir os quesitos de boas práticas e interatividade sem necessariamente disponibilizar maior quantidade de disclosure, seja compulsório ou voluntário. 


\section{REFERENCIAL TEÓRICO}

\subsection{TRANSPARÊNCIA DA GESTÃO NO SETOR PÚBLICO BRASILEIRO}

Segundo a Controladoria Geral da União (CGU), a transparência pode ser definida como "o ato de sabermos onde, como e por que o dinheiro está sendo gasto" (CGU, 2004), enquanto disclosure é entendido como a divulgação das informações voluntárias e compulsórias (HENDRIKSEN; BREDA, 1999; ARAÚJO, 2013).

A transparência é um conceito contextualizado por alguns autores (PLATT NETO et al., 2005; AVELINO et al., 2014; ZORZAL; RODRIGUES, 2015) em três dimensões, conforme Quadro 1:

Quadro 1: Dimensões da Transparência

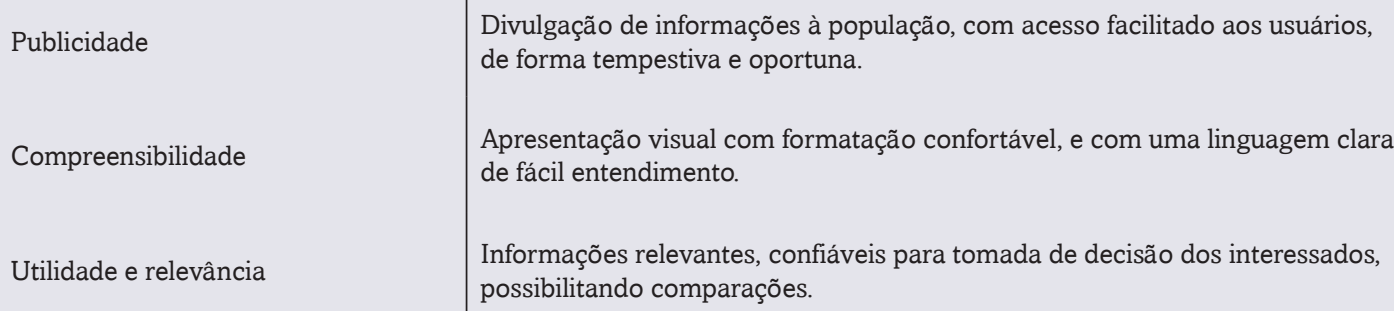

Fonte: Adaptado de Platt Neto et al. (2005)

Com base nessas características, a transparência pode ser entendida como um princípio de gestão fiscal instituído pela Lei de Responsabilidade Fiscal, que engloba o princípio constitucional da publicidade, além de estar associada aos conceitos de governança, evidenciação e responsabilidade pelos resultados (PLATT NETO et al., 2005).

O debate das finanças públicas inclui transparência das contas e dos atos do gestor público, permitindo fiscalização dos órgãos competentes (MARTINS, 2001), tendo o gestor dos recursos públicos duas responsabilidades básicas: agir e prestar contas de suas ações (GRAY, 2000). Assim, a transparência dos atos do gestor público torna-se primordial, com a edição da Lei 101/2000 (CRUZ et al., 2012) que "estabelece normas de finanças públicas voltadas para a responsabilidade na gestão fiscal" (LEI 101/2000).

Uma vez que, sendo a informação tutelada pelo Estado um bem público, cabe ao gestor público evidenciá-la de forma espontânea e proativa como definida em Lei (ZORZAL; RODRIGUES, 2015).

\subsection{EVIDENCIAÇÃO COMPULSÓRIA E VOLUNTÁRIA NO SETOR PÚBLICO}

As informações compulsórias são aquelas cuja divulgação é obrigatória por lei, como a Lei no 4.320/1964, a Lei Complementar no 101/2000 e o Manual de Contabilidade Aplicada ao Setor Público (MCASP), cujo intuito é fornecer aos usuários as informações de caráter econômico e financeiro. A Lei 9.755/1998 obriga a criação de "homepage na rede de computadores Internet" com informações como: I) Montantes de cada um dos tributos arrecadados pelo ente da federação, II) Relatórios resumidos da execução orçamentária de cada ente - RREO, III) Balanço consolidado das contas, suas autarquias e outras entidades, IV) Orçamentos do exercício (LOA) e os respectivos balanços do exercício anterior, V) Resumos dos instrumentos de contrato ou de seus aditivos e as ratificações, IV) Relações mensais de todas as compras feitas pela administração direta ou indireta.

Já a divulgação voluntária refere-se às informações que, embora não sejam obrigatórias por lei, são instrumentos importantes para complementação dos demonstrativos contábeis compulsórios por utilizar linguagem menos técnica e de fácil compreensão (FIPECAFI, 2000). Nesse sentido, o Parecer $n^{\circ}$ 15/87 da CVM inclui o relatório de administração para a gestão pública, para proporcionar maior clareza, variedade e qualidade aos relatórios exigidos pela Lei de Responsabilidade Fiscal.

No âmbito internacional, Bellver e Kaufmann (2005) desenvolveram um indicador de transparência para 194 países sob duas óticas - transparência econômica/institucional e transparência política. Os resultados apresentados sugerem que um maior nível de transparência, a nível nacional, não está associado a fatores culturais, geográficos ou financeiros, mas sim a melhores indicadores de desenvolvimento humano e socioeconômico, maiores níveis de competição política e baixos níveis de corrupção. Kolstad e Wiig (2009) indicam, entretanto, que apesar de a transparência ter efeitos sobre a corrupção, este efeito existe somente sob as condições de que os agentes que recebem a informação têm a habilidade necessária para processá-la, além do incentivo para utilizar tal informação, ou seja, depende do nível de educação dos receptores.

Em uma análise dos 100 maiores municípios da Espanha em 2008, Guillamón, Bastida e Benito (2011) relatam resultados indicando que fatores como maiores níveis de impostos per capita, transferências, tamanho da população e gestores de partidos de esquerda estão relacionados com maior transparência. Indicativos similares são encontrados por Sol (2013), para 110 munícipios espanhóis em 2010, que indica fatores como tamanho, ideologia do gestor e carac- 
terísticas institucionais, se o turismo é o setor econômico predominante e se o município é uma capital provincial, como determinantes da transparência nos governos locais.

Em contraposição aos resultados encontrados nos governos locais espanhóis, Alt et al. (2005) indicam que quanto mais equalitária a disputa política e a distribuição de poder, maior os níveis de transparência para os 48 estados norte-americanos entre 1976 e 1999 da amostra.

Para sumarizar os resultados sobre o tema, Bolívar, Muñoz e Hernández (2013) conduziram uma metanálise em 39 estudos entre sobre determinantes da transparência financeira em governos entre 1980 e 2011 . Apesar de os autores indicarem que as características dos estudos, como escolhas de indicadores ambientais e institucionais nos modelos empíricos, ano da publicação, esfera governamental e a cultura de gestão vigente afetam os resultados reportados, o estudo reporta vários determinantes da transparência pública, como condição financeira, reformas na gestão pública e padrões contábil-financeiros, transferências intergovernamentais, competição política, tamanho do município, renda per capita, entre outras.

Na literatura nacional, Cruz et al. (2012) indicam que, em geral, os municípios brasileiros possuem níveis de transparência relativamente baixos, se comparados com o tamanho do município, mas, ainda sim, confluindo com a literatura internacional, Avelino et al. (2014) ao analisarem 130 municípios mineiros em 2010, reportam o tamanho do município como um fator explicativo, além de variáveis políticas e do Índice Firjan de Desenvolvimento Municipal.

Por fim, Zuccoloto e Teixeira (2014) reportam que estados com melhores condições fiscais e socioeconômicas (Educação, Saúde, e Emprego e Renda) apresentam maior índice transparência fiscal, enquanto fatores políticos não apresentaram efeitos. Os autores também indicam, como Cruz et al. (2012), que os estados brasileiros apresentam baixos níveis de transparência. Marino et al. (2017) desenvolveram uma sumarização dos resultados da literatura brasileira, focando na quantidade e características dos estudos desenvolvidos, bem como os efeitos encontrados por estudos teóricos e empíricos.

\subsection{QUANTIDADE DE DISCLOSURE}

Tanto no setor público quanto privado, o tamanho do ente analisado influencia no nível de disclosure. Klann e Beuren (2011) analisaram tal característica com influente na divulgação das empresas, partindo do pressuposto que empresas maiores possuiriam maiores condições de suportar possiveis gastos com o sistema de divulgação. Tal afirmativa sustenta-se, para Lanzana (2004), ao investigar a existência da relação entre o nível de disclosure das companhias brasileiras de capital aberto e a governança corporativa destas. $O$ trabalho verificou que, dentre outras variáveis, o tamanho da empresa apresentava uma relação positiva e significativa com o nível de disclosure. O mesmo resultado foi encontrado por Braga, Oliveira e Salotti (2010) ao avaliarem a influência de determinadas variáveis econômicas sobre o nível de disclosure ambiental nos relatórios das empresas brasileiras.

Ademais, municípios maiores, em termos de receitas arrecadadas, teriam mais condições econômicas para implantar melhores portais eletrônicos e, consequentemente, divulgar mais informações (CRUZ et al., 2012).

Desse modo, Lima (2009) e Avelino et al. (2011) construíram um classificador de disclosure composto por 33 quesitos, tendo por obrigatórias aquelas informações definidas na Lei 9.755/1998 e LC 101/2000 e outras informações voluntárias, divulgados no site do município, agrupados em 6 (seis) grupos de informações: I - Informações Gerais; II - Informações Adicionais; III - Layout dos Relatórios; IV - Relatórios Adicionais; V - Situação Fiscal e Financeira; VI Informações Ambientais.

\subsection{RELAÇÃO ENTRE TRANSPARÊNCIA COM A QUANTIDADE DE DISCLOSURE}

Apesar do entendimento de que quantidade e qualidade do disclosure não medem necessariamente o mesmo fenômeno, a literatura empírica não apresenta uma desassociação clara entre quantidade, da qualidade, do disclosure, tanto no âmbito público quanto privado (BERETTA, BOZZOLAN, 2008). Beretta e Bozzolan (2008) propõem um framework para mensurar a qualidade do disclosure e, aplicando para 85 empresas italianas entre 1999 e 2001, demonstram que o indicador desenvolvido modela de forma mais realística o disclosure que utilizar apenas quantidade como proxy. $\mathrm{O}$ resultado é corroborado por Masruki, Hussainey e Aly (2018), que indicam que "tanto a qualidade quanto a quantidade de disclosure são importantes aspectos na preparação de relatórios anuais que atendam às expectativas dos diversos shareholders" (MASRUKI, HUSSAINEY, ALY, 2018).

Alotaibi e Hussainey (2016) ao investigarem os determinantes da quantidade e da qualidade do disclosure de Responsabilidade Social Corporativa das empresas na Arábia Saudita, entre 2013 e 2014, indicam que as empresas proveem grande quantidade de disclosure, porém de baixa qualidade. Ainda, a quantidade de disclosure está relacionada com tamanho do board, percentual de participação do governo, tamanho do comitê de auditoria e de remuneração enquanto a qualidade é ligada a fatores como tamanho do board, quantidade de diretores independentes e percentual de participação dos gestores.

Em um esforço no sentido de modelar o nível ótimo de disclosure informacional, Kolotilin (2014) deriva condições que indicam um trade-off entre quantidade e qualidade, sendo que o mecanismo ótimo irá encontrar um balanço entre essas duas características. 
Ao identificar os elementos que se refletem ao nível de transparência da administração pública, que se baseiam na Lei complementar $n^{\circ} 131 / 2009$ (Lei de Transparência) e na Lei $n^{\circ}$ 12.527/2011 (Lei de acesso à informação - LAI), e os quesitos que compõem o disclosure compulsório e voluntário, a presente pesquisa tenta verificar a seguinte hipótese:

H1: Quanto maior o índice de Transparência da Gestão Pública, menor é a quantidade de disclosure informacional dos municípios do Estado do Espírito Santo.

\section{METODOLOGIA}

A pesquisa pode ser classificada como descritiva, aplicando-se, para atender ao objetivo proposto, abordagem quantitava e explicativa, com procedimentos documentais, utilizando-se de dados extraídos dos portais de transparência dos 78 municípios capixabas e nos relatórios de avaliação de transparência no Ministério Público Estadual do Espírito Santo.

\subsection{COLETA DE DADOS}

Este trabalho correlacionou o índice de transparências da gestão dos 78 municípios do Estado do Espírito Santo, com base na LAI (Lei de Acesso à Informação), com a quantidade de disclosure informacional, em relação às informações compulsórias e informações voluntárias apresentadas pelos municípios capixabas nos âmbitos: Gerais; Adicionais; do Layout dos Relatórios; dos Relatórios Adicionais; da Situação Fiscal e Financeira; Ambientais e Legais, por meio de modelo econométrico para dados em painel com efeito fixo. A análise da influência do nível de transparência da gestão pública na quantidade de disclosure considerou os âmbitos das informações divididos em dois grandes grupos: o das informações compulsórias e o das informações voluntárias.

Desse modo, optou-se por construir um classificador do disclosure a partir dos quesitos da pesquisa de Lima (2009) e Avelino et al. (2011), adaptado para as necessidades dos municípios capixabas.

Os dados referentes ao nível de transparência dos municípios foram obtidos junto ao Ministério Público do Estado do Espírito Santo, o qual disponibilizou um banco de dados com observação de quarenta e seis quesitos distribuídos em três grupos de objetivos: estrutura da transparência; comunicação; boas práticas. Com relação à quantidade de disclosure, os dados foram extraídos dos sítios oficiais dos municípios e portais de transparência, cobrindo os anos de: 2013 , 2014, 2015 e 2016. O corte transversal foi assim determinado por compreender o início da prática da transparência por força da LAI e sua evolução temporal, em acompanhamento da inclusão das novas normas contábeis aplicadas ao setor público em observância à NBCASP.

O índice é composto por 37 quesitos adaptado do modelo de Avelino et al. (2011) com a inclusão das Informações Legais. Para esses quesitos foram atribuídos nota 0 no caso de falta de informação, nota 1 para o caso de informação somente qualitativa e nota 2 para o caso de informações qualitativas e quantitativas. Para a construção do índice, foram tidas por obrigatórias aquelas informações definidas na Lei 9.755/1998 e na LC 101/2000, divulgadas no site dos municípios, englobando um total de 7 (Sete) grupos de informações: I - Informações Gerais; II - Informações Adicionais; III - Layout dos Relatórios; IV - Relatórios Adicionais; V - Situação Fiscal e Financeira; VI - Informações Ambientais; e VII - Informações Legais, conforme Quadro 3.

Quadro 3: Abordagem dos Quesitos nos Grupos de Informações

\begin{tabular}{|c|c|c|}
\hline Grupos De Disclosure & Variável & Descrição da variável - Quesitos \\
\hline \multirow{4}{*}{$\begin{array}{c}\text { I - INFORMAÇÕES GERAIS - } \\
\text { (VOLUNTÁRIA) }\end{array}$} & V1 & Informações gerais sobre as instituições vinculadas ao Município \\
\hline & V2 & Informações gerais sobre o perfil socioeconômico da população \\
\hline & V3 & Informações sobre treinamento de funcionários \\
\hline & V4 & Informações sobre programas de incentivo à cultura \\
\hline \multirow{4}{*}{$\begin{array}{l}\text { II - INFORMAÇÕES } \\
\text { ADICIONAIS - } \\
\text { (VOLUNTÁRIA) }\end{array}$} & V5 & Informações sobre programas de assistência social \\
\hline & V6 & Informações sobre transporte urbano \\
\hline & V7 & Informações sobre processos licitatórios \\
\hline & V8 & Informações sobre audiências públicas \\
\hline $\begin{array}{l}\text { III - LAYOUT DOS } \\
\text { RELATÓRIOS }\end{array}$ & V9 & Utilização de recursos gráficos \\
\hline \multirow{3}{*}{$\begin{array}{l}\text { IV - RELATÓRIOS } \\
\text { ADICIONAIS - } \\
\text { (VOLUNTÁRIA) }\end{array}$} & V10 & Balanço Social \\
\hline & V11 & Balanço em Correção Monetária Integral \\
\hline & V12 & Relatório de Auditoria e Controle Interno \\
\hline
\end{tabular}




\begin{tabular}{|c|c|c|}
\hline Grupos De Disclosure & Variável & Descrição da variável - Quesitos \\
\hline \multirow{13}{*}{$\begin{array}{l}\text { V - SITUAÇÃO FISCAL } \\
\text { E FINANCEIRA } \\
\text { (COMPULSÓRIA) }\end{array}$} & V13 & Montante de tributos arrecadados \\
\hline & V14 & Relatório Resumido da Execução Orçamentária (RREO - conforme a LRF) \\
\hline & V15 & Balanço Orçamentário \\
\hline & V16 & Balanço Financeiro \\
\hline & V17 & Balanço Patrimonial \\
\hline & V18 & Demonstração das Variações Patrimoniais \\
\hline & V19 & Lei Orçamentária Anual - LOA \\
\hline & $\mathrm{V} 20$ & Contratos, aditivos e comunicações retificadas \\
\hline & V21 & Relações mensais das compras \\
\hline & V22 & Plano Plurianual - PPA \\
\hline & V23 & Lei de Diretrizes Orçamentárias - LDO \\
\hline & V24 & Prestação de Contas e o respectivo Parecer Prévio \\
\hline & V25 & Relatório de Gestão Fiscal (RGF - conforme a LRF) \\
\hline \multirow{8}{*}{$\begin{array}{l}\text { VI - INFORMAÇÕES } \\
\text { AMBIENTAIS - } \\
\text { (VOLUNTÁRIA) }\end{array}$} & V26 & Informações sobre Impactos Ambientais: reciclagem \\
\hline & V27 & $\begin{array}{l}\text { Informações sobre Impactos Ambientais: descontaminação e recuperação } \\
\text { de terras e águas }\end{array}$ \\
\hline & V28 & Informações sobre Impactos Ambientais: conservação de recursos naturais \\
\hline & V29 & Informação sobre Despesas em Investimento Ambiental \\
\hline & V30 & Informações sobre Educação Ambiental \\
\hline & V31 & Informações sobre Incentivos e Apoio à Pesquisas Ambientais \\
\hline & V32 & Informações sobre Reflorestamento \\
\hline & V33 & $\begin{array}{l}\text { Informações sobre Políticas de Tratamento de Água Utilizada e } \\
\text { Reutilização em Processos }\end{array}$ \\
\hline \multirow{4}{*}{$\begin{array}{c}\text { VII - INFORMAÇÕES LEGAIS } \\
\text { - (VOLUNTÁRIA) }\end{array}$} & V34 & Informações sobre a Lei Orgânica Municipal \\
\hline & V35 & Informações sobre o Plano Diretor Municipal (PDM) \\
\hline & V36 & Informações sobre o Código Tributário Municipal \\
\hline & V37 & Informações sobre os Programas de Trabalho (conforme o PPA) \\
\hline
\end{tabular}

Fonte: Adaptado de Avelino et al. (2011). O grupo VII foi adaptado ao modelo pelo autor.

Ao modelo de Avelino et al. (2011) foi incluído um quarto grupo de informações denominadas legais, uma vez que tais informações têm papel relevante na gestão dos municípios para evidenciar padrões, regras e normas legais que impactam na vida do cidadão e das empresas no decorre de suas atividades.

No que concerne ao nível de transparência da gestão dos municípios capixabas, optou-se em trabalhar com a referência classificatória do Ministério Público do Estado do Espírito Santo, que mediu a qualidade da gestão a partir de requisitos apresentados na Lei 12.527 de 18/11/2011, em que foram relacionados âmbito da transparência estrutural, comunicação e boas práticas, conforme apresentado no Quadro 4.

Quadro 4: Quesitos de Transparência da Gestão Pública

\begin{tabular}{|c|l|}
\hline Variável & Transparência Estrutural \\
1.1 & Inexistência de qualquer tipo de Relatório e/ou impossibilidade de sua localização. \\
1.2 & Divulgação parcial e/ou após o prazo de licitações, resultados e contratos. \\
1.3 & Divulgação do salário base dos servidores (folha de pagamento) \\
1.4 & Estrutura remuneratória \\
1.5 & Divulgação do cargo, vínculo e data de exercício dos servidores (folha de pagamento) \\
1.6 & Divulgação da matrícula dos servidores (na folha de pagamento) \\
1.7 & Divulgação parcial e/ou após o prazo do conjunto de Receitas da prefeitura
\end{tabular}




\begin{tabular}{|c|c|}
\hline Variável & Transparência Estrutural \\
\hline 1.8 & Divulgação parcial e/ou após o prazo do conjunto de Despesas da prefeitura \\
\hline 1.9 & Divulgação parcial e/ou após o prazo do conjunto de Despesas por Favorecido da prefeitura \\
\hline 1.10 & Divulgação parcial e/ou após o prazo do conjunto de Convênios da prefeitura \\
\hline 1.11 & Disponibilização da legislação em parte ou desatualizada \\
\hline 1.12 & Divulgação de licitações, resultados e contratos. \\
\hline 1.13 & Divulgação do nome dos servidores (na folha de pagamento) \\
\hline 1.14 & Divulgação da carga horária dos servidores (folha de pagamento) \\
\hline 1.15 & Divulgação das gratificações dos servidores (folha de pagamento) \\
\hline 1.16 & Divulgação do conjunto de Receitas incorridos no prazo de 3 meses \\
\hline 1.17 & Divulgação do conjunto de Despesas incorridos no prazo de 3 meses \\
\hline 1.18 & Divulgação do conjunto de Despesas por Favorecidos incorridos no prazo de 3 meses \\
\hline 1.19 & Divulgação do conjunto de Convênios incorridos no prazo de 3 meses \\
\hline 1.20 & Disponibilização de legislação completa e atualizada \\
\hline 1.21 & Divulgação de licitações, resultados e contratos com acesso total sem necessidade de login ou cadastro. \\
\hline 1.22 & Histórico de remunerações dos servidores \\
\hline 1.23 & Especificação detalhada da folha de pagt ${ }^{\circ}$ de servidores (descontos, abatimentos, indenizações, etc.) \\
\hline Variável & Transparência da qualidade da Comunicação \\
\hline 2.1 & Inexistência de qualquer tipo de indicador de transparência das atividades \\
\hline 2.2 & Site e portal da transparência da prefeitura desatualizados \\
\hline 2.3 & Horário de atendimento ao público \\
\hline 2.4 & Competências das secretarias \\
\hline 2.5 & Notícias atualizadas da prefeitura sobre ações, obras, programas e projetos \\
\hline 2.6 & Nome e funções dos secretários \\
\hline 2.7 & Banco de Perguntas e Respostas \\
\hline 2.8 & Endereço dos setores da prefeitura \\
\hline 2.9 & E-mail dos setores da prefeitura \\
\hline 2.10 & Telefone dos setores da prefeitura \\
\hline 2.11 & Redes Sociais \\
\hline 2.12 & Notícias das ações e/ou projetos em fase de tramitação \\
\hline Variável & Transparência de Boas Práticas e Interatividade \\
\hline 3.1 & Inexistência de qualquer tipo de canal para a participação dos cidadãos \\
\hline 3.2 & Glossário \\
\hline 3.3 & Formulário eletrônico \\
\hline 3.4 & Ouvidoria \\
\hline 3.5 & Regra dos 3 cliques \\
\hline 3.6 & Linguagem cidadã \\
\hline 3.7 & Download de informações \\
\hline 3.8 & Indicativo de retorno \\
\hline
\end{tabular}




\begin{tabular}{|c|l|}
\hline Variável & Transparência Estrutural \\
3.9 & Material Audiovisual \\
3.10 & Download de informações em formato aberto \\
3.11 & Acessibilidade (alto contraste, tamanho da fonte e outras ferramentas) \\
\hline
\end{tabular}

Fonte: Ministério Público do Estado do Espírito Santo (2015).

O resultado da correlação destas variáveis utilizadas pelo Ministério Público foi a classificação dos municípios do Estado do Espírito Santo pelo somatório dos percentuais das observações da Transparência Estrutural da Gestão Municipal (índice de transparências calculado para cada um dos municípios - ITM), Transparência da Comunicação (índice de Comunicação do Município - ICM) e a Transparência de Boas Práticas e Interatividade da Gestão Municipal (índice de Boas práticas - IBPI), levantamento nos municípios pelo Centro de Estudos e Aperfeiçoamento Funcional - CEAF/ MPES, sendo estes tratados e classificados em porcentagem de afirmativas positivas.

As observações foram calculadas em percentuais de informações disponibilizadas pelos municípios nas três categorias (Transparência Estrutural; Transparência da Comunicação e Transparência de Boas Práticas e Interatividade), conforme descrito do Quadro 5.

Quadro 5: Variáveis, Proxys e Descrições do Modelo

\begin{tabular}{|c|c|}
\hline Variável (Sigla) & Disclosure Informacional (DI\%): Situação Fiscal Financeira Obrigatória \\
\hline Descrição & $\begin{array}{l}\text { Variável dummy de informações obrigatórias financeiras, contábeis e orçamentárias, tendo a seguinte pontu- } \\
\text { ação: } 2 \text { pontos para informações com aspectos quantitativo e qualitativo, } 1 \text { ponto para informações somente } \\
\text { quantitativo e zero ponto pela ausência de informação, onde a somatória dos pontos de informações de cada } \\
\text { município é comparada ao máximo possível de pontos, obtendo um \% de informações disponibilizadas. }\end{array}$ \\
\hline Proxy & $\begin{array}{l}\text { Compreende informações no âmbito da Situação Fiscal e Financeira (V13 a V25): total de tributos arrecada- } \\
\text { dos; RREO - conforme a LRF; Balanço Orçamentário; Balanço Financeiro; Balanço Patrimonial; DVP; LOA; } \\
\text { contratos - aditivos - retificações; relação de compras; PPA; LDO; Parecer da prestação de contas; e RGF. }\end{array}$ \\
\hline Pont. Max. & 26 \\
\hline Variável (Sigla) & Disclosure Informacional (DI\%): Informações Voluntárias \\
\hline Descrição & $\begin{array}{l}\text { Variável dummy de informações voluntárias, tendo a seguinte pontuação: } 2 \text { pontos para informações com } \\
\text { aspectos quantitativo e qualitativo, } 1 \text { ponto para informações somente quantitativo e zero ponto pela ausên- } \\
\text { cia de informação, onde a somatória dos pontos de informações de cada município é comparada ao máximo } \\
\text { possivel de pontos, obtendo um \% de informações disponibilizadas. }\end{array}$ \\
\hline Proxy & Compreende informações: gerais; adicionais; layout dos relatórios; relatórios adicionais; ambientais; legais. \\
\hline Pont. Max. & 48 \\
\hline Variável (Sigla) & TRANSP\%: Transparência Estrutural \\
\hline Descrição & $\begin{array}{l}\text { Variável dummy de transparência estrutural, que assume o valor } 1 \text { para os municípios que cumpriram os } \\
\text { quesitos e } 0 \text { para os que não cumpriram, onde a somatória dos pontos de informações de cada município é } \\
\text { comparada ao máximo possivel de pontos, obtendo um \%. }\end{array}$ \\
\hline Proxy & De acordo com o Ministério Público do Estado do Espírito Santo (seja de transparência estrutural) \\
\hline Pont. Max. & 23 \\
\hline Variável (Sigla) & TRANSP\%: Transparência na qualidade da Comunicação \\
\hline Descrição & $\begin{array}{l}\text { Variável dummy de transparência da qualidade de comunicação, que assume o valor } 1 \text { para os municípios } \\
\text { que cumpriram os quesitos e } 0 \text { para os que não cumpriram, onde a somatória dos pontos de informações de } \\
\text { cada município é comparada ao máximo possível de pontos, obtendo um \%. }\end{array}$ \\
\hline Proxy & De acordo com o Ministério Público do Estado do Espírito Santo (transparência na comunicação) \\
\hline Pont. Max. & 12 \\
\hline Variável (Sigla) & TRANSP\%: Transparência de Boas práticas e Interatividade \\
\hline Descrição & $\begin{array}{l}\text { Variável dummy de transparência de boas práticas, que assume o valor } 1 \text { para os municípios que cumpriram } \\
\text { os quesitos e } 0 \text { para os que não cumpriram, onde a somatória dos pontos de informações de cada município } \\
\text { é comparada ao máximo possivel de pontos, obtendo um \%. }\end{array}$ \\
\hline Proxy & De acordo com o Ministério Público do Estado do Espírito Santo (transparência de boas práticas) \\
\hline Pont. Max. & 11 \\
\hline
\end{tabular}

Fonte: Elaborado pelo autor 
Ainda foram utilizadas variáveis de controle descritas no Quadro 6, cujas descrições encontram-se no apêndice, e foram extraídas do FIRJAN, tal como na pesquisa de Lima (2009) e Avelino et al. (2011).

Quadro 6: Descrição das variáveis de controle

\begin{tabular}{|c|c|}
\hline IFGF - GERAL & ÍNDICE FIRJAN DE GESTÃO FISCAL - GERAL \\
IFGF - RECEITA PRÓPRIA & ÍNDICE FIRJAN DE GESTÃO FISCAL - RECEITA PRÓPRIA \\
IFGF - GASTO C/PESSOAL & ÍNDICE FIRJAN DE GESTÃO FISCAL - GASTO C/ PESSOAL \\
IFGF - INVESTIMENTO & ÍNDICE FIRJAN DE GESTÃO FISCAL - INVESTIMENTO \\
IFGF - LIQUIDEZ & ÍNDICE FIRJAN DE GESTÃO FISCAL - LIQUIDEZ \\
IFGF - CUSTO DA DÍVIDA & ÍNDICE FIRJAN DE GESTÃO FISCAL - CUSTO DA DÍVIDA \\
\hline
\end{tabular}

Fonte: Adaptado do Sistema FIRJAN (2015)

\subsection{MODELO}

Com base nos estudos destacados ao longo desta pesquisa, buscou-se avaliar a influência no nível de transparência da gestão pública na quantidade de disclosure. compulsório e voluntário, entregues pelos municípios capixabas nos portais de transparência. A variação de quantidade de disclosure, em relação ao nível de transparência da gestão dos municípios, teve sua análise construída com base na equação (1), com descrições no Quadro 7:

$$
D I \%=\beta_{0}+\beta_{1} \text { TRANSP } \%+\text { Controles }+\varepsilon
$$

\section{Quadro 7: Descrição das Variáveis do Modelo}

\begin{tabular}{|c|l|}
\hline Variáveis & Descrição \\
DI\% & $\begin{array}{l}\text { Variável dependente medida em porcentagem da pontuação máxima observada nos } 37 \text { quesitos, tanto as } \\
\text { informações voluntárias como as compulsórias. } \\
\text { Variável independente em porcentagem da pontuação máxima dos quesitos referentes transparência estru- } \\
\text { tural, comunicação, boas práticas e interatividade. } \\
\text { TRANSP\% }\end{array}$ \\
Controles & liquidez e custo da dívida. \\
\hline
\end{tabular}

Fonte: Elaborado pelo Autor

O modelo relaciona índice de transparência com a quantidade de disclosure em porcentagem (para as informações de âmbito: Gerais; Adicionais; Layout dos Relatórios; Relatórios Adicionais; Situação Fiscal e Financeira; Informações Ambientais e Legais), controlado pelo índice FIRJAN de Gestão Fiscal, como objetivo de verificar se o nível de Transparência da Gestão explica a quantidade de disclosure informacional compulsório e voluntário divulgados pelos municípios.

Sendo assim, o modelo possibilitou analisar as seguintes relações: o impacto da transparência no disclosure compulsório com as variáveis de controle e sem as variáveis de controle; e o impacto da transparência no disclosure voluntário com as variáveis de controle e sem as variáveis de controle.

\section{RESULTADOS}

\subsection{ESTATÍSTICAS DESCRITIVAS}

Nesta pesquisa foram levantados os dados extraídos no site dos 78 municípios do Estado do Espírito Santo para os anos de 2013 a 2016, tanto das informações compulsórias quanto das informações voluntárias, analisados em painel com efeito fixo para análise dos quesitos de transparência e quantidade do disclosure.

A Tabela 1, a seguir, apresenta os resultados descritivos das variáveis aplicadas nos modelos.

Tabela 1: Estatística Descritiva

\begin{tabular}{l|c|c|c|c|c|c|c|c}
\hline Variable & N & Mean & S.D. & Min & $\mathbf{. 2 5}$ & Mdn & $\mathbf{. 7 5}$ & Max \\
\hline SIT_FISCAL_FIN_obrigat. percent & 312 & 0.32 & 0.21 & 0.00 & 0.19 & 0.31 & 0.42 & 0.92
\end{tabular}




\begin{tabular}{l|c|c|c|c|c|c|c|c}
\hline Variable & N & Mean & S.D. & Min & $\mathbf{. 2 5}$ & Mdn & $\mathbf{. 7 5}$ & Max \\
\hline INF. VOLUNTÁRIO_percent & 312 & 0.20 & 0.13 & 0.00 & 0.15 & 0.19 & 0.25 & 0.81 \\
Transparência Estrutural & 312 & 0.39 & 0.16 & 0.00 & 0.30 & 0.44 & 0.52 & 0.80 \\
Transp. Quali. Comunicação & 312 & 0.47 & 0.19 & 0.00 & 0.36 & 0.50 & 0.58 & 0.83 \\
Transp. Boas práticas e Inter & 312 & 0.45 & 0.22 & 0.00 & 0.33 & 0.50 & 0.58 & 0.92 \\
Ifgf geral & 214 & 0.56 & 0.10 & 0.19 & 0.50 & 0.57 & 0.63 & 0.80 \\
Ifgf receita própria & 214 & 0.27 & 0.19 & 0.02 & 0.14 & 0.20 & 0.35 & 1.00 \\
Ifgf gasto c/ pessoal & 214 & 0.51 & 0.20 & 0.00 & 0.48 & 0.54 & 0.60 & 1.00 \\
Ifgf investimento & 214 & 0.54 & 0.23 & 0.09 & 0.38 & 0.53 & 0.68 & 1.00 \\
Ifgf liquidez & 214 & 0.79 & 0.23 & 0.00 & 0.63 & 0.82 & 1.00 & 1.00 \\
Ifgf custo da dívida & 214 & 0.87 & 0.11 & 0.29 & 0.81 & 0.90 & 0.95 & 1.00 \\
\hline
\end{tabular}

Fonte: Dados da pesquisa

A estatística descritiva traz na coluna "N" o número de observações com 312 para transparência e disclosure e 214 observações para as variáveis de controle FIRJAN. Também os itens de disclosure foram agrupados em dois grupos: o primeiro (INF. VOLUNTÁRIO_percent) com as informações voluntárias referentes às informações: gerais, adicionais, layout, relatórios adicionais, ambientais e legais; e o segundo com as informações obrigatórias (SIT_FISCAL_FIN_obrigat. Percent).

A análise dos 78 municípios apresentou assimetria à esquerda com valores das medianas próximas do $3^{\circ}$ quartil e desvios padrões maiores entre as variáveis FIRJAN relativas à gestão fiscal, enquanto a variável "Informações Legais" (relativa à legislação do município) apresentou dispersão menor e média maior entre as variáveis

\subsection{RESULTADO DAS REGRESSÕES}

\subsubsection{Impacto da Transparência da Gestão Pública no Disclosure Compulsório}

Primeiramente, executaram-se as regressões do modelo econométrico que trata da relação entre o índice de transparência total com a quantidade do disclosure compulsório (SIT_FISCAL_FIN_obrigat. Percent), que compreende as informações contábeis/fiscais, controlado pelos índices FIRJAN de desenvolvimento do município e gestão fiscal. A Tabela 2, a seguir, apresenta os resultados do modelo.

Tabela 2: Disclosure Informacional Compulsório

\begin{tabular}{l|c|c|c|c|c|c}
\hline SIT_FISCAL_FIN_obrigat.\% & Coef. & Std. Err. & $\mathbf{t}$ & $\mathbf{P}>\mathbf{| t |}$ & $\mathbf{9 5 \%}$ Conf. & Intervalo \\
\hline Transparência Estrutural & .016986 & .0612851 & 0.28 & 0.782 & -.1041702 & .1381425 \\
Transp. Qual. Comunicação & -.107757 & .0609162 & -1.77 & 0.079 & -.2281849 & .0126693 \\
Transp. Boas práticas e inter. & -.353509 & .0689861 & -5.12 & 0.000 & -.4898907 & -.2171292 \\
Ifgf geral & 5.04003 & 2.743523 & 0.18 & 0.855 & -4.919 .754 & 5.927 .761 \\
Ifgf receita própria & -1.14362 & 6.180037 & -0.19 & 0.853 & -1.336 .113 & 1.107 .389 \\
Ifgf gasto c/ pessoal & -1.12988 & 6.173775 & -0.18 & 0.855 & -1.333 .501 & 1.107 .525 \\
Ifgf investimento & -1.12772 & 6.171789 & -0.18 & 0.855 & -1.332 .893 & 1.107 .348 \\
Ifgf liquidez & -1.1461 & 6.171377 & -0.19 & 0.853 & -1.334 .648 & 110.543 \\
Ifgf custo da dívida & -4.89567 & 2.747613 & -0.18 & 0.859 & -592.141 & 4.942 .274 \\
_cons & .4349923 & .1818498 & 2.39 & 0.018 & .0754877 & .7944968 \\
\hline
\end{tabular}

Fonte: Elaborado pelo Autor

As variáveis de "Boas Práticas" e "Qualidade da Comunicação" são significantes a 10\% e 1\% respectivamente, apresentando sinal negativo, não rejeitando $\mathrm{H} 1$ e indicando que pode haver de fato um trade-off entre quantidade e qualidade informacional, tudo mais constante. 
Na sequência, a Tabela 3 apresenta uma nova análise, aplicando a relação de disclosure compulsório com transparência, sem a utilização das variáveis de controle, para verificar quanto que a transparência explica a quantidade de disclosure informacional.

Tabela 3: Disclosure Informacional Compulsório

\begin{tabular}{l|c|c|c|c|c|c}
\hline SIT_FISCAL_FIN_\% & Coef. & Std. Err. & $\mathbf{t}$ & $\mathbf{P}>|\mathbf{t}|$ & $\mathbf{9 5 \%}$ Conf. & Interval \\
\hline Transparência & .0062134 & .0526728 & 0.12 & 0.906 & -.0975624 & .1099893 \\
Comunicação & -.1202837 & .0586549 & -2.05 & 0.041 & -.2358455 & -.004722 \\
Boas Práticas & -.4002602 & .057063 & -7.01 & 0.000 & -.5126857 & -.2878348 \\
_cons & .5594198 & .0197537 & 28.32 & 0.000 & .5205011 & .5983384 \\
\hline
\end{tabular}

Fonte: Dados da pesquisa

Os resultados sem as variáveis de controle utilizadas pela pesquisa indicam que maiores níveis de transparência na comunicação e boas práticas estão associados a 5\% e 1\%, respectivamente, com menores níveis de disclosure compulsório. A Transparência Estrutural não apresenta efeito significativo em nenhum dos dois casos (com e sem controle) para a amostra analisada.

\subsubsection{Impacto da Transparência da Gestão Pública no Disclosure Voluntário}

A Tabela 4 trata das análises do impacto do nível de transparência estrutural da gestão pública sobre a quantidade de disclosure informacional voluntário, tendo como variáveis de controle o índice FIRJAN de Gestão Fiscal: emprego e renda, receita própria, gasto com pessoal, investimento e custo da dívida dos municípios.

Tabela 4: Disclosure Informacional Voluntário

\begin{tabular}{l|c|c|c|c|c|c}
\hline VOLUNTARIO_\% & Coef. & Std. Err. & $\mathbf{t}$ & $\mathbf{P}>|\mathbf{t}|$ & [95\% Conf. & Interval] \\
\hline Transparência Estrutural & .013920 & .0242628 & 0.57 & 0.567 & -.0340454 & .0618866 \\
Transp. Qual. Comunicação & -.0465 & .0257344 & -1.81 & 0.073 & -.0973752 & .0043752 \\
Transp. Boas práticas e inter. & -.087363 & .0239318 & -3.65 & 0.000 & -.1346748 & -.0400516 \\
ifgf geral & -8.0980 & 1.160348 & -0.70 & 0.486 & -3.103 .733 & 1.484 .123 \\
ifgf receita própria & 1.81851 & 2.611988 & 0.70 & 0.487 & -3.345 .209 & 6.982 .234 \\
ifgf gasto c/ pessoal & 1.82327 & 2.610697 & 0.70 & 0.486 & -3.337 .889 & 6.984 .447 \\
ifgf investimento & 1.82559 & 2.610474 & 0.70 & 0.485 & -3.335 .134 & 6.986 .324 \\
ifgf liquidez & 1.81711 & 2.610348 & 0.70 & 0.488 & -3.343 .367 & 697.759 \\
ifgf custo da dívida & 8.21460 & 1.162335 & 0.71 & 0.481 & -1.476 .396 & 3.119 .318 \\
_cons & .1533637 & .0748465 & 2.05 & 0.042 & .0053974 & .3013301 \\
\hline
\end{tabular}

Fonte: Dados da pesquisa

A Tabela 5, traz a relação entre o disclosure voluntário com a transparência, sem as varáveis de controle, para avaliar a significância da transparência na explicação do disclosure voluntário.

Tabela 5: Disclosure Informacional Voluntário

\begin{tabular}{l|c|c|c|c|c|c}
\hline VOLUNTARIO_\% & Coef. & Std. Err. & $\mathbf{t}$ & $\mathbf{P}>|\mathbf{t}|$ & $\mathbf{9 5 \%}$ Conf. & Interval \\
\hline Transparência & .0117557 & .0210227 & 0.56 & 0.577 & -.0296631 & .0531746 \\
Comunicação & -.0599307 & .0231034 & -2.59 & 0.010 & -.105449 & -.0144124 \\
Boas práticas & -.1079419 & .0210954 & -5.12 & 0.000 & -.1495041 & -.0663798 \\
_cons & .2682894 & .0083726 & 32.04 & 0.000 & .2517937 & .2847852 \\
\hline
\end{tabular}

Fonte: Dados da pesquisa

Os resultados referentes à quantidade de disclosure voluntário são semelhantes aos encontrados em relação à 
quantidade de disclosure obrigatório, ou seja, analisando outros fatores constantes, Qualidade da Comunicação e Boas Práticas apresentam significância de $10 \%$ e $1 \%$, e sem controles, de $5 \%$ e $1 \%$, com sinal negativo do coeficiente, não rejeitando a $\mathrm{H} 1$ deste trabalho.

Conforme abordado no referencial teórico, há na literatura teórica a desassociação entre a quantidade e qualidade do disclosure informacional, apesar de o primeiro ser comumente usado como proxy para o segundo em estudos empíricos mais antigos.

Os resultados encontrados por este trabalho, tanto para disclosure compulsório quanto voluntário, indicam uma relação negativa entre os indicadores de transparência de qualidade da comunicação e transparência de boas práticas e interatividade com a quantidade de disclosure, indicando um trade-off entre essas duas características. A escolha dos gestores públicos tende a valorizar a obrigatoriedade legal, no cumprimento da LAI (Lei de Acesso à Informação) em detrimento de produzir informação, ou seja, o gestor se preocupa em cumprir os quesitos de boas práticas e interatividade sem efetivamente disponibilizar quantidade de disclosure, seja compulsória ou voluntária, à sociedade interessada.

\section{CONCLUSÃO}

O Índice de Transparência utiliza baseia-se na Lei 12.527 de 18/11/2011 e na Lei Complementar 131/2009, posteriormente regulamentada pelo decreto 7.185/2010, uma emenda à Lei de Responsabilidade Fiscal (LRF), a qual determina que todos os entes da federação das três esferas de poder disponibilizem na internet, em tempo real, informações pormenorizadas sobre a execução orçamentária e financeira.

Para fins deste estudo considerou-se as informações evidenciadas nos sites dos municípios capixabas nos anos de 2013 a 2016. Com base nos estudos destacados ao longo desta pesquisa, depreende-se observar se os municípios com maior nível de transparência da gestão pública entregam mais disclosure informacional divulgados nos portais eletrônicos dos municípios do Estado do Espírito Santo englobando um total de 7 (Sete) grupos de informações: I - Informações Gerais, II - Informações Adicionais, III - Layout dos Relatórios, IV - Relatórios Adicionais, V - Situação Fiscal e Financeira, VI - Informações Ambientais, e VII - Informações Legais; divididos em dois grandes grupos, agrupando-os de forma a considerar dois tipos de informação: compulsórias e voluntárias.

Os resultados encontrados sugerem uma associação negativa para a quantidade de disclosure informacional público e o nível de transparência em duas dimensões: Qualidade da Comunicação e Boas Práticas e Interatividade. A desassociação destas características do disclosure são uma importante contribuição para a literatura empírica, e os resultados encontrados são confluentes com a literatura teórica, mais especificamente com Kolotilin (2014).

Esses resultados podem indicar um trade-off entre quantidade e qualidade do disclosure, e também a preferência dos gestores municipais em valorizar a obrigatoriedade legal, no cumprimento da LAI (Lei de Acesso à Informação) em detrimento de produzir maior quantidade de informação, ou seja, o gestor se preocupa em cumprir os quesitos de boas práticas e interatividade sem necessariamente disponibilizar maior quantidade de disclosure, seja compulsória ou voluntária.

Diante das limitações da pesquisa, o estudo sugere que esta pesquisa seja ampliada em mais exercícios, sugerindo um estudo em painel com efeito fixo, aferindo assim uma análise maior, incluindo uma análise da evolução dos disclosure e no nível de transparências dos municípios capixabas, e adicionando as variáveis de controle tamanho da população.

\section{REFERÊNCIAS}

AHMED, K.; COURTIS, J. K. Association between corporate characteristics and disclosure levels in annual reports: a meta-analysis. British Accounting Review, Kindlinton n.31, p.35-61, 1999.

AKERLOF, G. The Market for Lemons: Qualitative Uncertainty and the Market Mechanism. Quarterly Journal of Economics, v. 84 , n. 3, p. 488-500, 1970.

ALOTAIBI, Khaleed Omair; HUSSAINEY, Khaled. Determinants of CSR disclosure quantity and quality: Evidence from non-financial listed firms in Saudi Arabia. International Journal of Disclosure and Governance, v. 13, n. 4, p. 364-393, 2016.

ALT, James E.; LASSEN, David Dreyer; ROSE, Shanna. The causes of fiscal transparency: evidence from the US states. IMF Staff papers, v. 53, n. 1, p. 30-57, 2006.

ARAÚJO, E. S. Disclosure Informacional: Aplicação em uma universidade pública federal. 2013.

AVELINO, B. C. et al. Divulgação voluntária do ente público: um olhar sobre o estado de Minas Gerais. Enfoque: Reflexão Contábil, v. 33, n. 1, 2014

AVELINO, B. C. et al. Índice de disclosure nos Estados Brasileiros: Uma abordagem da Teoria da Divulgação. IN: CONGRESSO USP DE INICIAÇÃO CIENTÍFICA EM CONTABILIDADE, 8., São Paulo, 2011. Anais... USP, 2011.

BAMBER, Linda Smith; JIANG, John; WANG, Isabel Yanyan. What's my style? The influence of top managers on voluntary corporate financial disclosure. The accounting review, v. 85, n. 4, p. 1131-1162, 2010.

BERETTA, Sergio; BOZZOLAN, Saverio. Quality versus quantity: the case of forward-looking disclosure. Journal of Accounting, Auditing \& Finance, v. 23, n. 3, p. 333-376, 2008.

BRAGA, J. P.; OLIVEIRA, J. R. S.; SALOTTI, B. M. Determinantes do nível de divulgação ambiental nas demonstrações contábeis de empresas brasileiras. Revista de Contabilidade da UFBA, v. 3, n. 3, p. 81-95, 2010. 
BRASIL. CONTROLADORIA-GERAL DA UNIÃO. Acesso à informação pública: uma introdução à Lei $\mathrm{n}^{\circ} 12.527$ de 18 de novembro de 2011. 2012

CONTROLADORIA GERAL DA UNIÃO. Olho vivo no dinheiro público: um guia para os cidadãos garantir os seus direitos. Brasília: Controladoria Geral da Uncruzião, 2004.

Decreto $\mathrm{n}^{\circ} 7.185 / 2010$. Dispõe sobre o padrão mínimo de qualidade do sistema integrado de administração financeira e controle, no âmbito de cada ente da Federação, nos termos do art. 48, parágrafo único, inciso lll, da Lei Complementar $\mathbf{n}^{\circ}$ 101, de 4 de maio de 2000, e dá outras providencias. Disponível em: <http//www.planalto.gov.br/ ccivil_03/_ato2007-2010/2070/decreto /d7185.htm>. Acesso em: 09 dez. 2015

Lei Complementar $\mathrm{n}^{\circ} 101$, de 4 de maio de 2000. Estabelece normas de finanças públicas voltadas para a responsabilidade na gestão fiscal e dá outras providências. Diário Oficial da República Federativa do Brasil, Brasília, 5 de maio 2000.

Lei Complementar $n^{\circ} 131$, de 27 de maio de 2009. Acrescenta dispositivos à Lei Complementar $\mathbf{n}^{\circ} 101$, de 4 de maio de 2000, que estabelece normas de finanças públicas voltadas para a responsabilidade na gestão fiscal e dá outras providências em tempo real, de informação pormenorizadas sobre a execução orçamentária e financeira da União, Estados, Distrito Federal e Municípios. Diário Oficial da República Federativa do Brasil, Brasília, 28 de maio 2009.

Lei $n^{\circ} 12.527 / 2011$. Regula o acesso aà informação previsto no inciso XXXlll do art. $5^{\circ}$, no inciso 11 do $\S 3^{\circ}$ do art. 37 e no $\S 2^{\circ}$ do art. 216 da Constituição Federal; altera a Lei n ${ }^{\circ} 8.112$, de 11 de dezembro de 1990; revoga a Lei 11.111, de 5 de maio de 2005, e dispositivo da Lei $n^{\circ}$ 8.159, de 8 de janeiro de 1991; e dá outras providências. Diário Oficial da República Federativa do Brasil, Brasília, 18 de novembro de 2011.

Lei no 4.320/1964, de 17 de março de 1964. Estatui normas gerais de direito financeiro para elaboração e controle dos orçamentos e balanços da União, estados, municípios e do Distrito Federal. Diário Oficial da República Federativa do Brasil, Brasília, 23 de mar. 1964.

Lei n ${ }^{\circ}$ 9.755/1998. Dispõe sobre a criação de "homepage” na "Internet”, pelo Tribunal de Contas da União, para divulgação dos dados e informações que especifica, e da outra providencias. Disponível em: <http://www.planalto.gov. br/ccivil/leis/L9755.htm>. Acesso em: 09 dez. 2015.

Manual de demonstrativos fiscais: aplicado à União e aos Estados, Distrito Federal e Municípios/ Ministério da Fazenda, Secretaria do Tesouro Nacional. 6. ed. - Brasília: Secretaria do Tesouro Nacional, Coordenação - Geral de Normas de Contabilidade Aplicadas à Federação, 2015. em: 20 nov. 2015 .

Parecer de Orientação CVM n. 15, de 28 de dezembro de 1987. Disponível em: <www.cvm.gov.br>. Acesso

CRUZ, C. F.; FERREIRA, A. C. de S.; SILVA, L. M.; MACEDO, M. Á. da S. Transparência da gestão pública municipal: um estudo a partir dos portais eletrônicos dos maiores municípios brasileiros. Revista de Administração Pública, Rio de Janeiro, v. 46, n.1. Jan./Feb. 2012. Disponivel em: <http://dx.doi.org/10.1590/S0034-76122012000100008>. Acesso em: 15 dez 2015.

CVM (Comissão de Valores Mobiliários). Recomendações da CVM sobre governança corporativa. Jun. 2002. Disponível em: <http://www.cvm.gov.br/port/public/publ/cartilha/cartilhadoc>. Acesso em: 20 nov. 2015.

DEMERJIAN, Peter R. et al. Managerial ability and earnings quality. The Accounting Review, v. 88, n. 2, p. 463-498, 2012.

FIPECAFI - Fundação Instituto de Pesquisas Contábeis, Atuariais e Financeiras. Manual de contabilidade das sociedades por ações: aplicável às demais sociedades. 5. ed. São Paulo: Atlas, 2000.

GARRETT, Jace; HOITASH, Rani; PRAWITT, Douglas F. Trust and financial reporting quality. Journal of Accounting Research, v. 52, n. 5, p. 1087-1125, 2014.

GE, Weili; MATSUMOTO, Dawn; ZHANG, Jenny Li. Do CFOs have style? An empirical investigation of the effect of individual CFOs on accounting practices. Contemporary Accounting Research, v. 28, n. 4, p. 1141-1179, 2011.

GRAY, R. H. Current developments and trends in social and environmental auditing, reporting and attestation: A review and comment. International Journal of Auditing, v. 4, n. 3, p. 247-268, 2000.

GUILLAMÓN, María-Dolores; BASTIDA, Francisco; BENITO, Bernardino. The determinants of local government's financial transparency. Local Government Studies, v. 37, n. 4, p. 391-406, 2011.

HENDRIKSEN, E. S; BREDA, M. F. V. Teoria da contabilidade. 1. ed. São Paulo: Atlas, 1999.

KAUFMANN, Daniel; BELLVER, Ana. Transparenting transparency: Initial empirics and policy applications. Available at SSRN 808664, 2005 .

KLANN, R. C.; BEUREN, I. M. Characteristics of companies that influence their voluntary disclosure of performance indicators. Brazilian Business Review, v. 8, n. 2, p. 92-113, 2011.

KOESTER, Allison; SHEVLIN, Terry; WANGERIN, Daniel. The role of managerial ability in corporate tax avoidance. Management Science, v. 63, n. 10, p. 3285-3310, 2016.

KOLOTILIN, Anton. Optimal information disclosure: Quantity vs. quality. UNSW Australian School of Business Research Paper, n. 2013-19, 2014.

KOLSTAD, I.; WIIG, A. Is transparency the key to reducing corruption in resource-rich countries? World Development, v. 37, n. 3, p. 521-532, 2009.

LANZANA, A. P. Relação entre disclosure e governança corporativa das empresas brasileiras. 2004. Tese de Doutorado. Universidade de São Paulo. 
LEWIS, Ben W.; WALLS, Judith L.; DOWELL, Glen WS. Difference in degrees: CEO characteristics and firm environmental disclosure. Strategic Management Journal, v. 35, n. 5, p. 712-722, 2014

LIMA, E. M. Análise comparativa entre o índice disclosure e a importância atribuída por stakeholders aà informações consideradas relevantes para fins de divulgação em Instituições de Ensino Superior Filantrópicas do Brasil: uma abordagem da Teoria da Divulgação. 2009. 200 f. Tese (Doutorado em Controladoria e Contabilidade) - Programa de Pós-Graduação em Controladoria e Contabilidade, Faculdade de Economia, Administração e Contabilidade da Universidade de São Paulo, São Paulo. Disponivel em: <http://www.teses.usp.br/teses/disponiveis/12/12136/tde-29052009-110807/>. Acesso em: 27 out. 2015.

LO, K.; RAMOS, F.; ROGO, R. Earnings management and annual report readability. Journal of Accounting and Economics, v. 63 , n. 1 , p. $1-25,2017$

MARINO, Pedro de Barros Leal Pinheiro et al. Public Transparency in the Brazilian Context: An Integrative Review. In: European, Mediterranean, and Middle Eastern Conference on Information Systems. Springer, Cham, 2017. p. 261-274.

MARTINS, P. Introdução: Acesso à informação como direito humano fundamental. In: CANELA, G.; NASCIMENTO, G. S. Acesso à informação e controle social das políticas públicas. Brasília: ANDI, 2009. p. 9-31.

MASRUKI, Rosnia; HUSSAINEY, Khaled; ALY, Doaa. Developing Accountability Disclosure Index for Malaysian State Islamic Religious Councils (SIRCs): Quantity and Quality. Management \& Accounting Review (MAR), v. 17, n. 1, p. 1-18, 2018.

NAKAGAWA, M. Accountability: a razão de ser da contabilidade. Revista Contabilidade \& Finanças, São Paulo, v. 18, n. 44, p. 7-7, maio/ago. 2007.

NIYAMA, J. K.; DANTAS, J. A.; ZENDERSKY, H. C.; SANTOS, S. C. A dualidade entre os benefícios do disclosure e a relutância das organizações em aumentar o grau de evidenciação. Revista Economia e Gestão, Belo Horizonte, v.5, n. 11, p. 56-76, dez. 2005.

PLATT NETO, O. A. et al. Publicidade e transparência nas contas públicas: obrigatoriedade e abrangência desses princípios na administração pública brasileira. In: CONGRESSO USP DE CONTROLADORIA E CONTABILIDADE, 5, 2005, São Paulo. Anais... São Paulo: FEA/USP 2005

RODRÍGUEZ BOLÍVAR, Manuel Pedro; ALCAIDE MUÑOZ, Laura; LÓPEZ HERNÁNDEZ, Antonio M. Determinants of financial transparency in government. International Public Management Journal, v. 16, n. 4, p. 557-602, 2013.

SECRETARIA DO TESOURO NACIONAL. Manual de contabilidade aplicada ao setor público: aplicado à União, Estados, Distrito Federal e Municípios/Ministério da Fazenda, Secretaria do Tesouro Nacional. 4. ed. - Brasília: Secretaria do Tesouro Nacional, Coordenação-Geral de Normas de Contabilidade Aplicada à Federação, 2011.

SILVA, C. A. T.; NIYAMA, J. K. Teoria da contabilidade. 2. ed. São Paulo: Atlas, 2012

SISTEMA FIRJAN - Federação das Indústrias do Estado do Rio de Janeiro: Índice de desenvolvimento municipal ano base 2013. Rio de Janeiro, 2015. Disponível em: <www.firjan.com.br>. Acesso em: 15 dez. 2015.

SISTEMA FIRJAN - Federação das Indústrias do Estado do Rio de Janeiro: Índice de gestão fiscal ano base 2013. Rio de Janeiro, 2015. Disponível em: <www.firjan.com.br>. Acesso em: 15 dez. 2015.

SLOMSKI, V. Controladoria e governança na gestão pública. São Paulo: Atlas SA, 2000. 140 p.

SOL, Daniel Albalate del. The institutional, economic and social determinants of local government transparency. Journal of Economic Policy Reform, v. 16, n. 1, p. 90-107, 2013

SPENCE, M. Job market signaling. The quarterly journal of Economics, v. 87, n. 3, p. 355-374, 1973

SUNDFELD, C. A. Princípio da publicidade administrativa (Direito de certidão, vista e intimação). Revista de Direito Administrativo, v. 199, p. 97-110, 1995.

ZORZAL, L.; RODRIGUES, G. M. Disclosure e transparência no setor público: uma análise da convergência dos princípios de governança. Informação \& Informação, Londrina, v. 20, n. 3, 113-146, set/dez 2015.

ZUCCOLOTTO, Robson; TEIXEIRA, Marco Antonio Carvalho. As causas da transparência fiscal: evidências nos estados brasileiros. Revista Contabilidade \& Finanças-USP, v. 25, n. 66, p. 242-254, 2014. 